\title{
A “BIRD's Eye ViEW" on COMMUNiCATION ACTS IN A ClassRoom OF Low Literacy Adults
}

\author{
Carlos Luís ${ }^{1,2}$, Helena Afonso ${ }^{3}$ and Maria José Marcelino ${ }^{1}$ \\ ${ }^{1}$ CISUC and FCTUC Universidade de Coimbra, Portugal \\ ${ }^{2}$ IEFP-Centro de Formação Profissional de Coimbra, Portugal \\ ${ }^{3}$ IEFP-Delegação Regional do Centro IEFP Coimbra; Portugal
}

\begin{abstract}
This paper starts by discussing the relevance of dialogues in Adult Education and Training courses with low levels of literacy. In this group, the educational challenges are complex, and innovating the knowledge creation process involves a better understanding of the teaching/learning process. With these case study, we pretend to understand which Communicative Acts are effective in adult learning process, mainly in adults with low literacy. Based on a mixed methods, applied to a convenience sample, we used an ethnographic approach, and the Grounded Theory Methodology. Using the Contextual Design approach, we developed several models of the context (work models) and got a bird's-eye view of the way the communicational acts and the dynamic acts flow in the classroom. The results showed that it was important to integrate the learners' emotions in an existing framework, the SEDA Framework. We found also essential to expand the Communicative Acts coding, with a new set of 17 codes organized in 3 categories in order to understand better the flow of communication in the classroom.
\end{abstract}

\section{KEYWORDS}

Adult Education; Literacy; Classroom acts; learning environments; Human-Computer-Interaction.

\section{INTRODUCTION}

Adults education with low levels of literacy is a fundamental condition for the full exercise of citizenship in contemporary societies, because "Education must aim at the full expansion of the human personality and the reinforcement of human rights [...]" [1]. We are facing fundamental educational challenges for this adult population, which has to face the constant changes and technological developments introduced in our daily lives.

The quality of adult teaching/learning comprises communication, reorganizing learning environments, qualifying and training teachers, and assessing and validating acquired skills among others.

In this context, it is crucial to study the dialogues between teacher-learner / learner-teacher in order to improve the understanding of these teaching/learning processes. It is also important to understand the flow of communication in the classroom.

Adult teaching/learning is characterized by its complexity, diversity of practices and contexts [2]. One of the concerns of this type of education is unequivocally related to the problem of the dialogue. The dialogue is a method of teaching and learning and one of the materials from which a learner constructs meaning (Edwards \& Mercer, 1987), cited by D. Myhill[3]. Paulo Freire 
argued that education "is an exchange between people and, it can never be done by an isolated person (even self-education is a distance dialogue)" [4].

Communication therefore plays one of the relevant and important roles in this interactive, dynamic and complex process, being categorized into different types of events [5] - the so-called communicational events (EC).

Learning environments also generate a diversity of emotional experiences that impact the entire teaching/learning process [6]. In this sense, the study of emotions in this context allows us to introduce another component of study that may contribute to a better understanding of the complexity of the processes involved, as emotions may be important indicators of the underlying motivations and cognitions [7]. In this sense, Pekrun et al. [8], highlight that emotions in the context of teaching-learning are significantly linked to the learners motivation, the pedagogical strategies, cognitive and performance resources, personality, as well as the events experienced in the classroom.

This paper is organized in 9 sections. Following the introduction, section 2 defines literacy and identifies its different levels. Section 3 describes the concept and definition of Communicative Events, section 4 is dedicated to the Emotions in the classroom, and the Work models of Contextual Design are presented in section 5. In section 6 we briefly describe the characteristics of the case under study, the methodology used, and the characteristics of the sample. The results of the research are presented in section 7. Section 8 offers the analysis and discussion of the results and section 8 presents a brief conclusion.

\section{UNDERSTANDINGS OF LITERACY}

The assessment of cognitive and workplace skills needed to advance at work and participate in society was the objective of the Programme for the International Assessment of Adult Competencies (PIAAC), commissioned by Organisation for Economic Co-operation and Development(OECD), and was based on two previous studies with adults (16-65 years old): The International Adult Literacy Survey (IALS) and the Adult Literacy and Life's kills Survey (ALL). PIAAC identified three domains of literacy Skills [9]:

Literacy [9]: "Ability to understand, evaluate, use and engage with written texts to participate in society, to achieve one's goals, and to develop one's knowledge and potential;" [9]

Numeracy [9]: "Ability to access, use, interpret, and communicate mathematical information and ideas in order to engage in and manage the mathematical demands of a range of situations in adult life;"

Problem solving in technology-rich environments [9]: "Ability to use digital technology, communication tools and networks to acquire and evaluate information, communicate with others and perform practical tasks."

The measurement range of scores for each scale was 0 to 500. For each scale, five levels of literacy were defined [10]:

- Level 1 People with very poor skills. People can read relatively short digital or printed texts to locate a single piece of information.

- Level 2 People can paraphrase or make low-level inferences and can deal only with material that is simple, clearly laid out. It denotes a weak level of skill. 
International Journal on Integrating Technology in Education (IJITE) Vol.10, No.2, June 2021

- Level 3 People should understand complex text, interpret, one or more pieces of information. They should construct significances across larger parts of text or perform multistep operations in order to identify and express opinions.

- Levels 4 People should perform multiple-step operations to integrate, interpret or combine information from complex or multiple types of texts.

- Levels 5 People can search for, and integrate, information across multiple, dense texts; construct syntheses of similar and contrasting ideas or points of view; or evaluate evidenced based arguments.

With this description it is possible to provide a clear picture of adult proficiency in literacy, numbering and problem solving skills, and to understand if they are prepared for a better social integration and living conditions.

Having detailed the domain of literacy and its levels, in the next section we describe the concept and definition of communication.

\section{Communication Models}

Communication is an essential element of the teaching-learning process and has been acquiring more and more visibility. Understanding the role of dialogue in learning and in the development of learners, should involve the whole community, making clear its importance and its implications for adult education and social integration.

John Fiske, in his work, Introduction to Communication Studies, outlines the existence of two major schools of investigation [11]: the process school and the semiotic school. The first sees communication as a linear process, where the transmitter places the information on a channel that takes it to the receiver. The second is based on the semiotic model, where relevance is placed on the creation of meanings and the creation of messages. In this model, the content and the communication process are inseparable and their analysis comprises the study of the signs used and the cultures in which they are integrated [12] and the way messages interact with learners, in order to generate meaning.

From a sociocultural perspective, teaching/learning is a dialogical process between the learner and the teacher in contexts that reflect the values and social behaviours of schools as cultural institutions [13]. According to N. Mercer [13], the quality of the educational dialogue is essential in the success or failure in the process. The teacher is responsible for the construction of the dialogical language and the main inputs producer. Quoting Paulo Freire, "It is not in silence that men make themselves, but in the word, at work, in action-reflection" [14].

Based on these facts, communication is an integrating concept, which allows the transmission and sharing of knowledge, ideas and information. For Van Dijk [15, p. 2], a communicative event is the result of the interaction between two people who express ideas or emotions in a verbal or nonverbal way [15, pp. 6-7] - through the presentation of codes (gestures, eye movements or voice features) that transmit messages exclusively in that context [11].

Hymes[16], reflects on the structure and organization of the discourse where there are rules or norms, called communicative situation (or speech), well defined hierarchically by units of analysis (events). Thus, the communicative event (CE) will always comprise one or more communicative acts (CA). Taking into account this well-defined hierarchy, we can state that a communicative situation (SC) includes one or more $\mathrm{CE}$, which, in turn, comprises one or more CA - Fig. 1. For Hymes, communicative situations are composed beyond speech by other types 
of events, not subject to communication rules, but dependent on the context. As a whole, language is without any doubt the most ubiquitous, flexible and creative tool of production and exchange of knowledge [17, p. 2], being the educational instrument by excellence, both at the pedagogical level and at the level of orientation of the teaching / learning process, being the object of investigation in several areas of knowledge.

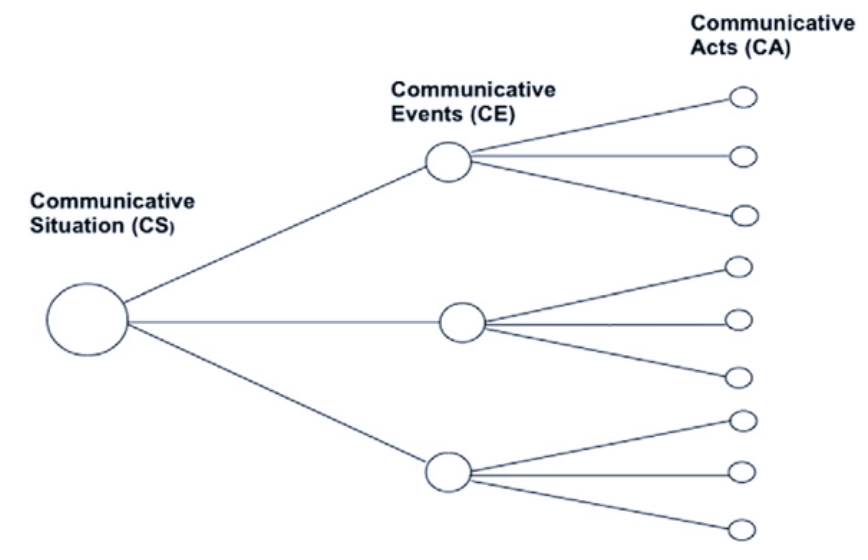

Figure 1. Hierarchical and nested levels - Source: Developing a coding scheme for analysing classroom dialogue across educational contexts

Paying more attention to the Communicative Acts (CA) in the classroom Hennessy et al. [18] [20], focused on the systematic analysis of the dialogues, where each situation provides a certain number of information that can be coded and grouped. For such, they developed a framework called Scheme for Educational Dialogue Analysis (SEDA), Cambridge University - United Kingdom and National Autonomous University (UNAM) - Mexico. This framework of 33 codes, grouped into 8 categories [19], enables the analysis and interpretation of videos and/or audios collected, according to the CA framework, which allows the identification and study of the dialogues' acts by their function within an interaction. These studies are based on tools resulting from the Sociocultural Discourse Analysis [21]. According to Mercer, the Sociocultural Discourse Analysis seeks to understand the communicational acts, framed by its sociocultural context. In addition, it aims to explain how participants acquire a set of new knowledge over different time ranges. With this framework, the 'dialogic teaching-and-learning' (DTL) is the main analytical focus, involving the communicative interactions between teachers and learners, enabling the development of knowledge, skills and related behaviours in the classroom [21].

SEDA identifies these CA by their function within an interaction. Working at this micro-level is particularly enlightening since it allows carrying out fine-grained, systematic analyses of what learners actually do and say in practice during these dialogic interactions.

\section{EMotions in the Classroom}

Research in the context of classroom interactions, which generate and are the result of emotions, has recorded a noticeable increase in recent years, but, according to Pekrun[22], few studies have taken place in the context of teaching / learning, with two exceptions: a) test anxiety; b) emotions linked to success and failure. For Pekrun et al. and Schutz et al. [23] [24] [25] [7], educational contexts are marked by strong emotional experiences, capable of impacting teaching / learning processes, personal development, motivation and self-regulation. 
International Journal on Integrating Technology in Education (IJITE) Vol.10, No.2, June 2021

Schutz, Hong, Cross and Osbon[25] concluded that emotions are socially created and personally activated, emerging from conscious and/or unconscious opinions regarding success/failure in the effort to achieve goals, in an interaction between the individual and the social environment.

Pekrun[26][27][28] and collaborators studied emotions in the academic context and developed the theory of the control-value of achievement emotions as an integrated model when considering the teaching/learning context when the learner feels in control, or out of control, of the activities and their outcomes. The perception of control or lack thereof is another factor that can assist to its success.

The control-value theory is based on a three-dimensional taxonomy of achievement emotions [[26][27][28][29]: 1) object focus (activity focus vs outcome focus); 2) its valence (positive vs. negative, or pleasant vs. unpleasant); 3 ) the degree of activation (activating vs. deactivating).

\section{Contextual Design}

Contextual Design (CD) is a user-centered design process, developed by Beyer and Holtzblatt in 1988 that has been used, since then, in a wide variety of industries and taught in universities all over the world [30], with the aim to understand the customer and the context in order to find out their fundamental intents, desires, and drivers [31]. CD is divided into two major phases [31]: (I) Requirements and solutions; (II) Define and validate concepts. CD is a step-by-step process, it is intrinsically linked to, and its development is nourished by, multiple design and research methodologies. It takes a cross-functional team for collecting data about the learner in the field and through interpretation and consolidation of that data and understanding its relevance to his/her problems in a real-world context [32].

CD uses graphical representations, based on the data collection (work models), and simplifies picturing the problems. These models aim to convey the details, in order to see the purposes, strategies and motivations that control the way work is carried out [31].Below we described some of them:

- The Flow Model in CD represents how work is broken up between people and how it is coordinated to get the whole activity done. It represents the individuals involved in a particular task and the communication and coordination necessary to achieve it. According to Beyer and Holtzblatt [33] it offers a bird's-eye view of all work [31], [33, pp. 89-96].

- The Sequence Model is equivalent to a task analysis, it identifies a main task which is carried out and expresses it as an intent. These models are ordered and unfold over time. They show the entire sequence of steps completed to perform a set of tasks and to achieve a given goal [31], [33, pp. 171-178].

\section{Characteristics of The Study}

In this case study we adopted a mixed-methods approach according to a sequential exploratory design (QUAL $\rightarrow$ QUAN) [34], [35], regarding a convenience sample [34], [35]withtwogroupsbelonging to the Centro de Formação do Instituto do Emprego e Formação Profissional of Coimbra. The first group was a group of learners from the Basic Skills Program, with 300 hours of lessons which include Reading and Writing, Information and Communication Technologies and Math, and where learners can acquire basic skills that allow and stimulate them to proceed with further training The second group was a group of learners from the Adult Education and Training B1+B2 - with three main areas: 1) basic skills - 850 hours of lessons; 2) 
learning with autonomy - 40 hours of lessons; 3) Technological learning - 350 hours of lessons, and gives learners the possibility of acquiring both school qualifications and professional skills.

With the study of this two groups our purpose was to identify and understand, once removed the aspects that are related to the idiosyncrasies of the studied case, Communicative Acts that can be found in similar groups [36, pp. 121-143]. Based on this assumption we can formulate the following Research Questions (R.Q.): a) What types of Communicative Acts are linked to the teaching/learning process of adults with low literacy? b) Do all Communicative Acts contribute to this process? c) Are there any other types of acts that are present in the learning process? d) How communication flows?

In order to answer the set of questions that outline the rational of this research, the data collection was based on ethnographic research, taking the teachers perspective, "emic perspective" [37], [38], to collect data - filming, pictures and field notes captured during some sessions of the Reading and Writing training unit of this class, which allows to 're-create' the teaching/learning process. The observation was not directed by any observation script, according to Eriksson \&Kovalainen's naturalist theory [37, pp. 149-162].

The qualitative analysis of the collected data followed some essential principles [35, pp. 232 253]: (I) organize and prepare the data; (II) carefully read and analyse the data; (III) identify and codify the data; (IV) analyse the contents. In this research data processing and qualitative analysis was done using the Computer Assisted Qualitative Data Analysis Software (CAQDAS) - NVivo 12. To use NVivo we adopted the principles and procedures of the codification of data as stated in its specific literature [38]-[40], following the traditional Grounded Theory steps, of a constructivist nature: open, axial and selective coding [41], enabling the content analysis [40] and the information selection. Regarding the systematically analysis of the dialogue in the CA classroom, the Scheme for Educational Dialogue Analysis Framework (SEDA) of 33 codes, grouped into 8 categories [19], was used in order to identify and study the dialogue acts by their function within an interaction [20]. In order to evaluate the emotions experienced by the students during the activity, according to the control-value theory, we based ourselves only in the second dimension valence. (positive - vs negative, or pleasant vs unpleasant) Table 2, because observing facial and postural emotional expressions in the classroom would be therefore used for analysing learners and teachers.

The specific strategies used to answer questions about scientific credibility in qualitative studies, in the perspective of Lincoln and Guba (1991), cited by Coutinho [42], are: "Triangulation; Member checking; Rich, thick description; Negative case analysis; Prolonged engagement; Peer debriefing; External Auditing" [43], [44].

In order to ensure the scientific reliability/credibility of this study and to reduce or control bias, three teachers involved in the education/training of adults (peer debriefers) participated in this study, with whom we hold meetings, where we discussed issues, strategies, ideas and concerns related to it.

\subsection{Sample Characteristics}

The first group was formed by 28 learners from Coimbra, aged between 21 and 56 years (average $\approx 42 \mathrm{y}$ ), from which $46 \%$ were female. The second group was composed by 18 learners from Figueira da Foz, aged between 18 and 59 years (average $\approx 42 y$ ), $83 \%$ of which were female. The learners were advised to attend this programme in order to create new opportunities for social integration, since they were unemployed with a family at "risk of social exclusion". 


\section{DESCRIPTION OF THE RESUlTS}

These results are based on the monitoring and coding of several videos, pictures and field notes captured during some sessions of the training unit mentioned in the section about features of the study.

In a first stage of this exploratory analysis, the video transcription was carried out in such a way that it faithfully replicated the learners' dialogues and was used as the source to make a corpus ${ }^{1}$ for the analysis [40].

In a second stage, an alignment between the NVivo functionalities, and in an inductive perspective [38, pp. 113-127], a cyclical and interactive process was used to "extract" meanings and identify concepts ${ }^{2}$ [40] until reaching the "theoretical saturation ${ }^{3 "}$ [38, pp. 113-129], bearing in mind the objectives of this research: a) to think/understand the context (ontological question); and then it was possible to idealize the CA occurrence and also the presence of other type of acts not covered by SEDA b) determine the influence of the educational context and its variables in the teaching/learning process (epistemological question).

Starting by SEDA we could quantify the repetitive communicational acts observed. Through the observation of the first group Table 1 we verified that the communicational acts of the teacher were more frequent than those of the learners ( $70 \%$ versus $30 \%$ ). The results obtained allow us to verify that out of the 8 categories of the SEDA the I - Invite elaboration or reasoning was the most frequent $28 \%$, followed by the $\mathrm{C}$ - Connect and $\mathrm{P}$ - Positioning and Coordination both with $22 \%$. Category B - Build on ideas, in turn, was the least used (1\%), preceded by categories R Make reasoning explicit (4\%) and RD - Reflect on dialogue or activity (5\%). From this first analysis it is pointed out that there is a small incidence of negative emotions (2\%).

Table 1. Repetitive communicational acts (first group)

\begin{tabular}{|c|c|c|c|c|c|}
\hline & $C 0^{*}$ & Learner & & teacher & \\
\hline & CA & Neg. & Pos. & Neg. & Pos. \\
\hline B - Build on ideas & B1 & 0 & 0 & 0 & 2 \\
\hline & Total & 0 & $\mathbf{0}$ & $\mathbf{0}$ & 2 \\
\hline C-Connect & $\mathrm{C} 1$ & 0 & 0 & 0 & 12 \\
\hline & $\mathrm{C} 2$ & 0 & 0 & 0 & 51 \\
\hline & Total & 0 & 0 & 0 & 63 \\
\hline $\mathrm{G}$ - Guide direction of & $\mathrm{G} 2$ & 0 & 0 & 0 & 13 \\
\hline & G3 & 0 & 0 & 0 & 8 \\
\hline & G4 & 0 & 1 & 0 & 30 \\
\hline & G5 & 0 & 0 & 0 & 2 \\
\hline & Total & 0 & 1 & 0 & 53 \\
\hline I - Invite elaboration or & I4 & 0 & 15 & 0 & 66 \\
\hline reasoning & I5 & 0 & 0 & 0 & 1 \\
\hline & Total & 0 & 15 & 0 & 67 \\
\hline $\mathrm{P}-$ Positioning and & $\mathrm{P} 3$ & 5 & 48 & 0 & 11 \\
\hline Coordination & Total & 5 & 48 & 0 & 11 \\
\hline $\mathrm{R}-$ Make reasoning & $\mathrm{R} 2$ & 0 & 13 & 0 & 0 \\
\hline & Total & $\mathbf{0}$ & 13 & $\mathbf{0}$ & $\mathbf{0}$ \\
\hline
\end{tabular}

Set of documents to be submitted for analysis procedures [40]

Concepts are given labels.

New or relevant data which does not repeat itself. 
International Journal on Integrating Technology in Education (IJITE) Vol.10, No.2, June 2021

\begin{tabular}{|l|l|c|c|c|c|}
\hline \multirow{2}{*}{} & \multirow{2}{*}{ CA $^{*}$} & \multicolumn{2}{|c|}{ Learner } & teacher & \\
\cline { 3 - 6 } & & Neg. & Pos. & Neg. & Pos. \\
\hline \multirow{2}{*}{$\begin{array}{l}\text { RD - Reflect on } \\
\text { dialogue or activity }\end{array}$} & RD1 & 0 & 2 & 0 & 3 \\
\cline { 2 - 6 } & RD3 & 0 & 5 & 0 & 4 \\
\cline { 2 - 6 } & Total & 0 & 7 & 0 & 7 \\
\hline \multicolumn{2}{|c}{ Total } & $\mathbf{5}$ & $\mathbf{8 4}$ & $\mathbf{0}$ & $\mathbf{2 0 3}$ \\
\hline
\end{tabular}

B1 - Build on /clarify others' contributions; C1 - Refer back; C2 - Make learning trajectory explicit; G2 - Propose action or inquiry activity; G3 - Introduce authoritative perspective; G4 - Provide informative feedback; G5 - Focusing; I4 - Ask for explanation or justification; I5 - Invite possibility thinking or prediction; P3 - Propose resolution; R2 - Explain or justify own contribution; RD1- Talk about talk; RD3 - Invite reflection about process/ purpose/ value/ outcome of learning [19].

We have identified also some other acts, activities or strategies (that we called Dynamic Acts DA), not included in the SEDA framework, and that may modify the quality of the teaching/learning process (see Table 2). The analysis and discussion of other individual and/or group actions presented in the learning environment can become more complete. The most common DA was BE - Behavioral acts (62\%). We found a higher frequency (55\%) of DA linked to the learner. It is worth to emphasize the existence of a high incidence of negative motivations $(22 \%)$ in the behavioural group (BE - Behavioral acts).

Table 2. Dynamic Acts (first group)

\begin{tabular}{|c|c|c|c|c|c|}
\hline & \multirow{2}{*}{$\mathrm{DA}^{*}$} & \multicolumn{2}{|c|}{ Learner } & \multicolumn{2}{|c|}{ teacher } \\
\hline & & Neg. & Pos. & Neg. & Pos. \\
\hline \multirow[t]{8}{*}{ BE -Behavioral acts } & BE1 & 1 & 14 & 0 & 4 \\
\hline & BE2 & 0 & 1 & 0 & 0 \\
\hline & BE3 & 0 & 4 & 0 & 0 \\
\hline & BE4 & 6 & 0 & 0 & 0 \\
\hline & BE5 & 1 & 1 & 0 & 0 \\
\hline & BE6 & 13 & 17 & 5 & 40 \\
\hline & BE7 & 0 & 9 & 0 & 0 \\
\hline & Total & 21 & 46 & 5 & 44 \\
\hline \multirow[t]{7}{*}{ LA - Learning acts } & LA1 & 1 & 5 & 0 & 3 \\
\hline & LA2 & 0 & 4 & 0 & 1 \\
\hline & LA3 & 0 & 2 & 0 & 0 \\
\hline & LA4 & 0 & 2 & 0 & 0 \\
\hline & LA5 & 0 & 0 & 0 & 0 \\
\hline & LA6 & 0 & 1 & 0 & 1 \\
\hline & Total & 1 & 14 & $\mathbf{0}$ & 5 \\
\hline \multirow[t]{5}{*}{ S - Strategic acts } & S1 & 0 & 12 & 0 & 6 \\
\hline & S2 & 0 & 0 & 0 & 15 \\
\hline & S3 & 1 & 7 & 0 & 3 \\
\hline & S4 & 1 & 1 & 9 & 0 \\
\hline & Total & 2 & 20 & 9 & 24 \\
\hline \multicolumn{2}{|l|}{ Total } & 24 & 80 & 14 & 73 \\
\hline
\end{tabular}

*BE1 - Sit up /down; BE2 - Clear the white board; BE3 - Get out/in; BE4 - Watch the mobile phone; BE5 - Answer the mobile phone; BE6 - Talk; BE7 - Everybody talks; LA1 - Write on the notebook, LA2 - Write on the white board; LA3 - Search text; LA4 - Reading; LA5 - Reading aloud; LA6 - Sign the attendance sheet; S1 Ask for help; S2 - Positive reinforcement; S3 - Humor; S4 - Reprehension. 
International Journal on Integrating Technology in Education (IJITE) Vol.10, No.2, June 2021

Regarding the second group, it is possible to observe, in Table 3, that the frequency of communication acts was balanced - Teacher $51 \%$ versus $49 \%$ of Learners. The acquired results obtained, based on the SEDA categories, the $\mathrm{G}$ - Guide direction of dialogue or activity was the most frequent $48 \%$, followed by the RD - Reflect on dialogue or activity $20 \%$ and the I - Invite elaboration or reasoning with $19 \%$. Furthermore, the categories C - Connect (1\%) and B - Build on ideas (2\%) were the least used, preceded by the category $\mathrm{R}$ - Make reasoning explicit (9\%). From this first analysis, it must be stressed the existence of $11 \%$ of CA that provoked negative emotions on the learners.

Just like in the first group, a series of DA not identified by SEDA was identified (see Table 4), being the $\mathrm{BE}-$ Behavioral acts the most frequent (59\%) of DA linked to the student. The behavioural group ( $\mathrm{BE}-$ Behavioral acts) is the one which presents the highest frequency of negative emotions (30\%)

Table 3. Repetitive communicational acts (second group)

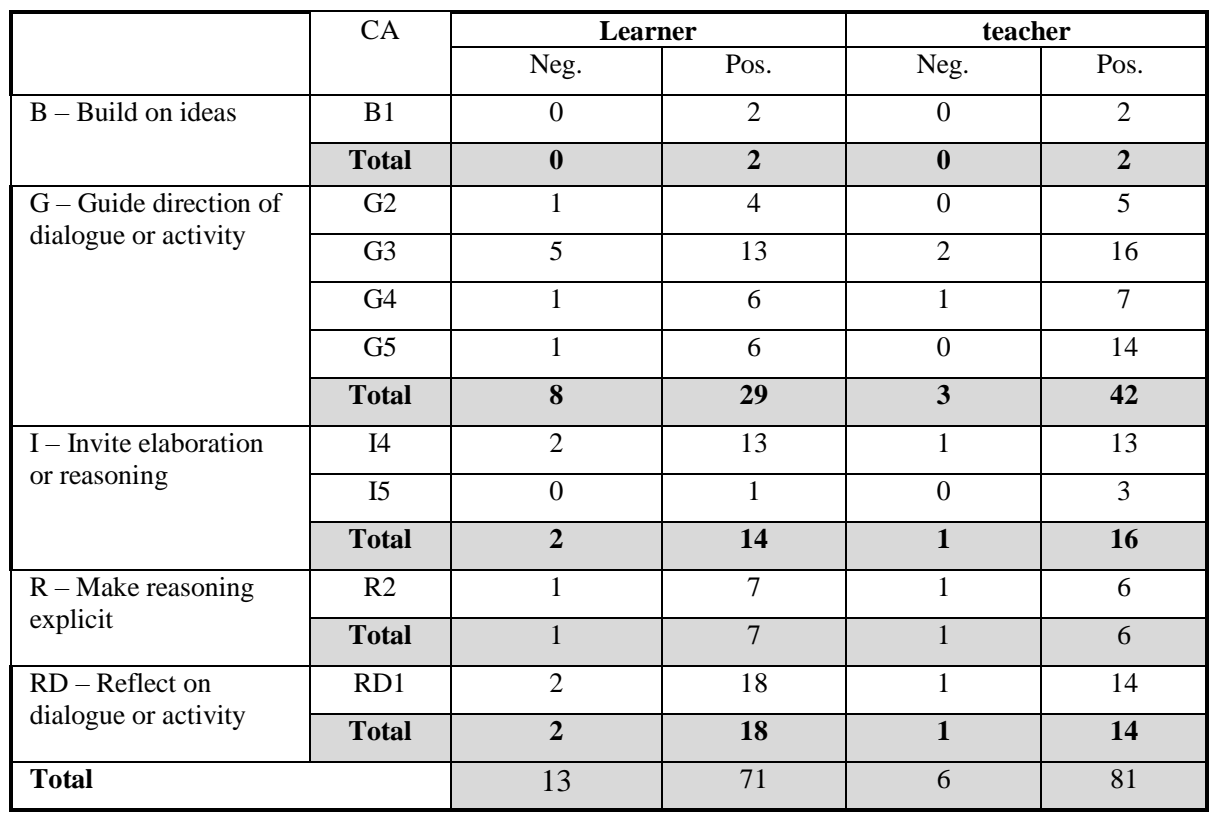

Table 4. Dynamic Acts (second group)

\begin{tabular}{|l|c|c|c|c|c|}
\hline \multirow{4}{*}{} & \multirow{2}{*}{ DA } & \multicolumn{2}{|c|}{ Learner } & \multicolumn{2}{c|}{ teacher } \\
\cline { 3 - 7 } & & Neg. & Pos. & Neg. & Pos. \\
\hline BE-Behavioral acts & BE2 & 0 & 1 & 0 & 2 \\
\cline { 2 - 6 } & BE3 & 2 & 6 & 1 & 4 \\
\cline { 2 - 6 } & BE4 & 1 & 1 & 1 & 1 \\
\cline { 2 - 6 } & BE6 & 3 & 5 & 1 & 4 \\
\cline { 2 - 6 } & BE7 & 5 & 8 & 2 & 6 \\
\cline { 2 - 6 } & Total & $\mathbf{1 1}$ & $\mathbf{2 1}$ & $\mathbf{5}$ & $\mathbf{1 7}$ \\
\hline LA - Learning acts & LA1 & 4 & 7 & 1 & 6 \\
\cline { 2 - 6 } & LA2 & 3 & 4 & 1 & 7 \\
\cline { 2 - 6 } & LA5 & 0 & 12 & 0 & 6 \\
\cline { 2 - 6 } & LA6 & 0 & 1 & 0 & 1 \\
\cline { 2 - 6 } & Total & $\mathbf{7}$ & $\mathbf{2 4}$ & $\mathbf{2}$ & $\mathbf{2 0}$ \\
\hline S - Strategic acts & S1 & 2 & 4 & 0 & 5 \\
\hline
\end{tabular}


International Journal on Integrating Technology in Education (IJITE) Vol.10, No.2, June 2021

\begin{tabular}{|l|c|c|c|c|c|}
\hline \multirow{4}{*}{} & \multirow{3}{*}{ DA } & \multicolumn{2}{|c|}{ Learner } & \multicolumn{2}{c|}{ teacher } \\
\cline { 3 - 7 } & & Neg. & Pos. & Neg. & Pos. \\
\cline { 2 - 6 } & S2 & 1 & 2 & 0 & 2 \\
\cline { 2 - 7 } & S3 & 0 & 3 & 0 & 1 \\
\cline { 2 - 7 } & S4 & 3 & 3 & 2 & 2 \\
\cline { 2 - 7 } & Total & $\mathbf{6}$ & $\mathbf{1 2}$ & $\mathbf{2}$ & $\mathbf{1 0}$ \\
\hline Total & $\mathbf{2 4}$ & $\mathbf{5 6}$ & $\mathbf{9}$ & $\mathbf{4 6}$ \\
\hline
\end{tabular}

The next models (Consolidation models) are seldom designed for a single learner. They are the sample view without losing the individual learner. Using that consolidated data, CD helps us to have a "bird's-eye view" of all the work.

In a following step, based on the direct observation of the video and pictures taken during the learning process and in the analysis of descriptive and reflective notes of the events, obtained in the real context, it was possible to draw how the information flows, related to the experience lived by the learners, Figure 2, and thus, obtain a flow model of the learning process. One of the positive aspects of this model is the extreme simplification of reality that can be inferred from it. The flow of information is then always seen in a transversal way, establishing links between the various sources of information: people - represented by ovals; artefacts - represented by rectangles.

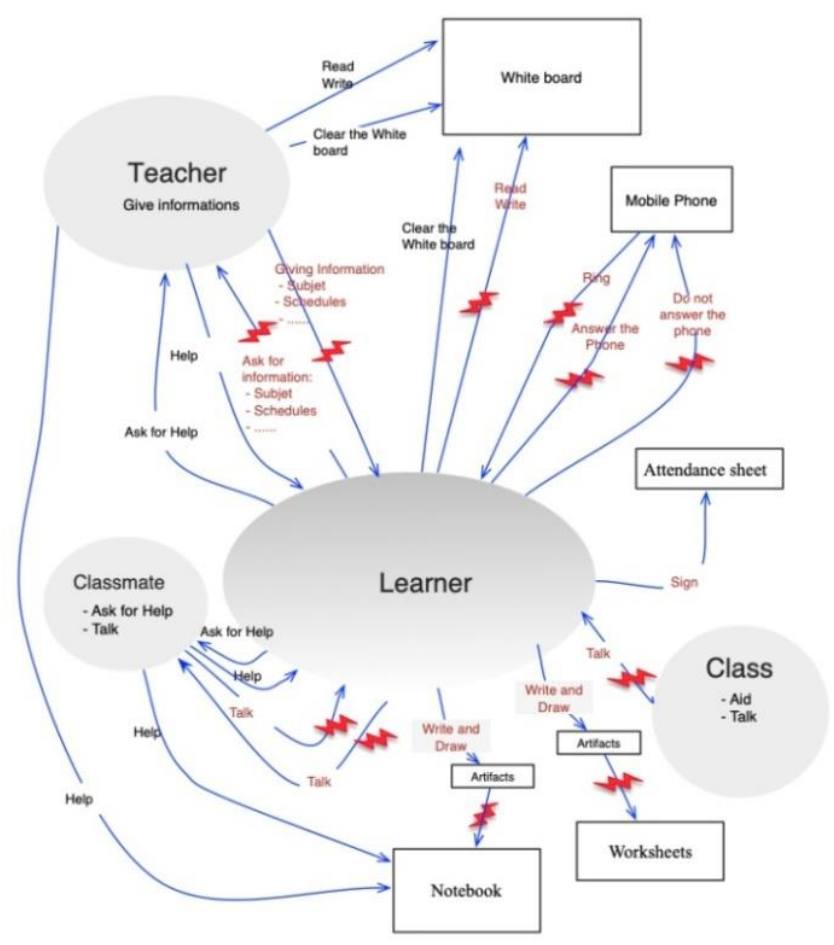

Figure 2 - Consolidated flow model of the study - Source: [45]

In the middle of the consolidation flow model is the learner, shown as an ellipse. Other relevant people are drawn as a set of annotated ellipses, artefacts are shown in rectangles. Communication 
between people and artefacts is shown by arrows on the diagram with arrowheads indicating the direction of the communication and breakdowns are shown by a lightning flash.

The consolidated sequential model, Figure 3, is equivalent to a task analysis. This consolidated model brings together many instants of learners accomplishing the same activity, the order and strategy for doing it. The activity started with a notification to the learner, start the action (trigger). The arrows indicate the sequence of steps and breakdowns are shown by a lightning flash

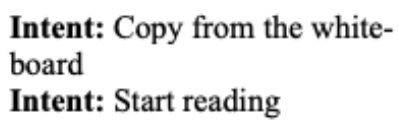

Trigger: The teacher started to write on the whiteboard Open the notebook, picking the pen, $\downarrow$ Put the glasses on, look to the whiteboard

Ask for aid

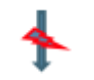

Read the text, write the text

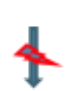

Look for the eraser

Mobile phone ring

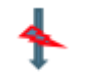

Look to the notebook, look to the whiteboard

\section{$\downarrow$}

Close the notebook, Put the glasses off

\section{$\downarrow$}

clear the desk

Figure 3. Consolidated sequential model of the study - Source: [45]

\section{Analysis Of THE Results}

In order to answer the research questions, it was necessary to integrate the emotions of the learners with the SEDA Framework. This integration was based on the Pekrun and collaborators, theory of control-value of achievement emotions [26][27][28]. From all the three categories of emotions we only used the second one - during the activity according to their valence (positive vs negative)

A new set of three acts' categories emerged (Dynamic Acts - DA) creating 17 codes Table 5, in result of the material collected and the carefully and critically reading of the data obtained from the classroom. This table enables the summary of practices, knowledge, attitudes and strategies that contribute significantly to the purpose of this case study. 
Table 5 - Dynamic Acts (DA)

\begin{tabular}{|c|c|c|}
\hline Cluster & Description & Concepts \\
\hline BE -Behavioral acts & $\begin{array}{l}\text { Coding individual or group } \\
\text { Behavioral acts that are } \\
\text { witnessed in the learning } \\
\text { environment and that have } \\
\text { influence, directly or indirectly, } \\
\text { in the acquisition of knowledge. }\end{array}$ & $\begin{array}{l}\text { BE1 - Sit up /down; } \\
\text { BE2 - Clear the white } \\
\text { board; } \\
\text { BE3 - Get out/in; } \\
\text { BE4 - Watch the mobile } \\
\text { phone; } \\
\text { BE5 - Answer the mobile } \\
\text { phone; } \\
\text { BE6 - Talk; } \\
\text { BE7 - Everybody talks }\end{array}$ \\
\hline LA - Learning acts & $\begin{array}{l}\text { Identifying different types of acts } \\
\text { that are part of the learning } \\
\text { process. }\end{array}$ & $\begin{array}{l}\text { LA1 - Write on the } \\
\text { notebook } \\
\text { LA2 - Write on the white } \\
\text { board } \\
\text { LA3 - Search text } \\
\text { LA4 - Reading } \\
\text { LA5 - Read aloud; } \\
\text { LA6 - Sign the attendance } \\
\text { sheet; }\end{array}$ \\
\hline S -Strategic acts & $\begin{array}{l}\text { Identifying different types of } \\
\text { strategies that are part of the } \\
\text { process. }\end{array}$ & $\begin{array}{l}\text { S1 - Ask for help } \\
\text { S2 - Positive reinforcement } \\
\text { S3 - Humour } \\
\text { S4 - Reprehension. }\end{array}$ \\
\hline
\end{tabular}

We can see, through the CAs of the two groups (Table 1. And Table 4), the importance of contexts and their influence on communication and discursive practices. Asymmetries can be seen not only in the type of CA but also in terms of the emotions experienced.

It is important to underline that in the first group, the I - Invite elaboration or reasoning (28\%) was the most significant during the teaching/learning process, followed by the $\mathrm{C}$ - Connect (22\%) and the I - Invite elaboration or reasoning (22\%).

However, this did not happen in the second group, where the CA G - Guide direction of dialogue or activity (48\%) played a leading role, followed by the RD - Reflect on dialogue or activity $(20 \%)$.

It is relevant to emphasize that the emotions experienced by the learners are different in the two groups, in the first we found $94 \%$ of positive emotions - Table 1, and in the second $85 \%$ of positive emotions - According to Meyer and Turner [12] positive emotions contribute to build a good learning environment, enabling an empathic relationship between all actors in the process.

In the LA - Learning Acts identified with codes LA1 - LA5, the frequencies obtained show that most of the activities are positive in both groups - 92\% in the first and $77 \%$ in the second Table 1, 0This evidence linked with the high percentage of I - Invite elaboration or reasoning, represents significant and essential variables for the learners' encouragement and motivation. This standpoint is supported by the model developed by Carroll, "Model of School Learning"[36], in which the amount of time devoted to study or to a learning activity is an evidence of motivation and contributes to the success of teaching/learning.

On the contrary, the negative impact of some Behavioral acts, which are not directly related to the task, called "off-task behaviour" [37][38], Table 2 and Table 4, have destabilizing effects in this process. 
International Journal on Integrating Technology in Education (IJITE) Vol.10, No.2, June 2021

The analysis of Figure 2 shows the efficiency or inefficiency of the information flow. In this process it is appropriate to highlight the number of transmitters and/or receivers and the high number of artefacts required for oral and written communication. Based on Clark \&Paivio's Double Coding Theory [46], which explains the limited processing capacity of visual/pictorial and auditory/verbal stimuli, there is a high flow of information that could be harmful to the learning environment.

In order to understand how leaners achieved their learning goals, we show the whole sequence of steps to accomplish it in a specific activity, Figure 3. In this activity there may exist several breaks that make it difficult and that can be harmful to the class.

\section{Conclusions}

This case study had as main objective to reflect/understand the influence of dialogue and emotions experienced by learners (adults with low literacy level) in the teaching/learning process. For such, we used a mixed method approach following a (QUAL-> QUAN).

We concluded that other types of acts were essential in the learning process. In fact, we have combined the learners' emotions with the SEDA's framework and we observed that it is fundamental to complement the coding of the CA's, emerging a new set of 3 categories and 17 codes. Positive emotions were found to be essential for the construction of healthy learning environments, enabling an empathic relationship between all stakeholders in the process.

In the LA, most activities worked as an enabling and integrating element, allowing the learners to be more involved. Throughout the whole teaching/learning process, reading and writing stand out as important activities, thus allowing the promotion of these two transversal skills.

We would say that being a teacher implies reordering and reinventing pedagogical instruments that facilitate educational intervention and the learning process carried out by the learner. The appropriate use of DA is essential in relationships, which are not always assertive, between: teacher/learner; learner/teacher; learner/learner. Conditions that contribute to a bad environment hamper activities and the acquisition of knowledge, and DA that motivate the learners are critical in their participation and performance. Excessive participation may be harmful to the educational context, as witnessed by our "peer debriefers".

With the flow model and sequential model, it was possible to determine the efficiency or inefficiency of the flow of information, allowing a distinction between the number of transmitters and/or receivers and the necessary artefacts to support communication. With these two models we can understanding the CA and the DA as they are and get a "bird's-eye view" of the process.

This case study supplements the elements that we had previously presented [45], where we reviewed aspects like flow of information, artefacts to support communication, cultural influences, actors in the educational process, the organization of the learning space, the pedagogical methods, that can influence learning and allow a better knowledge of the learning environment and of the mental model of this population. With these two studies we want to minimize the uncertainties associated with these closed spaces, in order to enrich systematically and comprehensively compared multiple Human-Computer-Interaction (HCI) interfaces to Faceto-Face (F2F).

We intend in this way to complete the knowledge about the learning environments experienced by these learners in order to design them in a more accessible way making learning more attractive and integrative. 
International Journal on Integrating Technology in Education (IJTTE) Vol.10, No.2, June 2021

\section{ACKNOWLEDGEMENTS}

We would like to express our gratitude to the Board of Directors of IEFP of Coimbra, Portugal, as well as to all the learners of this training module of the Basic Competences Program and the learners of the Adult Education and Training B1+B2. For their inputs, our thanks are extended to peer debriefers invited to assess and validate the results, Cristina Coroado, João Gomes and Olga Reis

\section{REFERENCES}

[1] United Nations General Assembly, "The Universal Declaration of Human Rights," 1948.

[2] P. D. Ávila, A literacia dos adultos: competências-chave na sociedade do conhecimento. 2005.

[3] D. Myhill, "Talk, talk, talk: Teaching and learning in whole class discourse," Res. Pap. Educ., vol. 21, no. 1, pp. 19-41, 2006.

[4] C. R. Brandão, O que é método Paulo Freire. Brasiliense, 2017.

[5] M. Saville-Troike, "The Ethnographic Analysis of Communicative Events," Sociolinguistics, pp. 126-144, 1997.

[6] L. Mata, F. Peixoto, V. Monteiro, C. Sanches, and M. Pereira, "Emoções em contexto académico: Relações com clima de sala de aula, autoconceito e resultados escolares," Anal. Psicol., vol. 33, no. 4, pp. 407-424, 2015.

[7] D. K. Meyer and J. C. Turner, "Re-conceptualizing Emotion and Motivation to Learn in Classroom Contexts," Educ. Psychol. Rev., vol. 18, no. 4, pp. 377-390, 2006.

[8] R. Pekrun, T. Goetz, W. Titz, and R. P. Perry, “Academic Emotions in Students' Self-Regulated Learning and Achievement: A Program of Qualitative and Quantitative Research," Educ. Psychol., vol. 37, no. 2, pp. 91-105, Jun. 2002.

[9] OECD, "Education \& Skills Online Assessed," OECD. [Online]. Available: https://www.oecd.org/skills/ESonline-assessment/skillsassessed/. [Accessed: 23-Jan-2020].

[10] OECD, The Survey of Adult Skills: Reader's Companion. OECD Publishi, 2013.

[11] J. Fiske, Introduction To Communication Studies. 2002.

[12] A. Fidalgo and A. Gradim, Manual de semiótica. Covilhã: Universidade da Beira Interio, 2007.

[13] N. Mercer, "Sociocultural Discourse Analysis: Analysing Classroom Talk as a Social Mode of Thinking," J. Appl. Linguist., vol. 4, no. 2, pp. 1-15, 2004.

[14] P. Freire, Pedagogia do Oprimido, Paz \&Terr. Rio de Janeiro, 1981.

[15] T. A. Van Dijk, Discourse as structure and process, vol. 1. Sage, 1997.

[16] D. Hymes, "Models of the Interaction of Language and Social Life: Toward a Descriptive Theory," Intercultural Discourse and Communication. pp. 4-16, 01-Jan-2005.

[17] N. Mercer and K. Littleton, Dialogue and the development of children's thinking: a sociocultural approach. London, UK: Routledge, 2007.

[18] S. Hennessy, "Analysing Video Recordings of Classroom Lessons Using the Scheme for Educational Dialogue Analysis ( SEDA )," SAGE, pp. 1-7, 2018.

[19] S. Hennessy et al., "Developing a coding scheme for analysing classroom dialogue across educational contexts," LCSI, vol. 9, pp. 16-44, 2016.

[20] S. Hennessy, "Analysing Video Recordings of Classroom Lessons Using the Scheme for Educational Dialogue Analysis," SAGE Publ. Ltd., 2017.

[21] N. Mercer, "The analysis of classroom talk: Methods and methodologies," pp. 1-14, 2010.

[22] R. Pekrun, "Progress and open problems in educational emotion research," Learn. Instr., vol. 15, no. 5, pp. 497-506, 2005.

[23] R. Pekrun, T. Goetz, W. Titz, and R. P. Perry, “Academic emotions in students' self-regulated learning and achievement: A program of qualitative and quantitative research," Educ. Psychol., vol. 37, no. 2, pp. 91-105, 2002.

[24] R. Pekrun, A. J. Elliot, and M. A. Maier, "Achievement goals and discrete achievement emotions: A theoretical model and prospective test," J. Educ. Psychol., vol. 98, no. 3, pp. 583-597, 2006.

[25] P. A. Schutz, J. Y. Hong, D. I. Cross, and J. N. Osbon, "Reflections on Investigating Emotion in Educational Activity Settings," Educ. Psychol. Rev., vol. 18, no. 4, pp. 343-360, 2006.

[26] R. Pekrun, A social-cognitive, control-value theory of achievement emotions, vol. 131, no. C. Elsevier Masson SAS, 2000. 
International Journal on Integrating Technology in Education (IJITE) Vol.10, No.2, June 2021

[27] R. Pekrun, "The control-value theory of achievement emotions: Assumptions, corollaries, and implications for educational research and practice," Educ. Psychol. Rev., vol. 18, no. 4, pp. 315-341, 2006.

[28] R. Pekrun, A. C. Frenzel, T. Goetz, and R. P. Perry, "The Control-Value Theory of Achievement Emotions. An Integrative Approach to Emotions in Education.," Emot. Educ., pp. 13-36, 2007.

[29] R. Pekrun and E. J. Stephens, “Achievement Emotions : A Control-Value Approach,” vol. 4, pp. 238$255,2010$.

[30] K. Holtzblatt and H. Beyer, "Contextual Design: Evolved," Synth. Lect. Human-Centered Informatics, vol. 7, no. 4, pp. 1-91, 2014.

[31] J. M. Carroll, "The Encyclopedia of Human-Computer Interaction, 2nd Ed.," II Encyclopedia of Human - Computer Interaction, 2014. [Online]. Available: https://www.interactiondesign.org/literature/book/the-encyclopedia-of-human-computer-interaction-2nd-ed.

[32] K. Holtzblatt, J. Burns Wendell, and S. Wood, Rapid Contextual Design - A How-to Guide to Key Techniques for User Centered Design. 2005.

[33] H. Beyer and K. Holtzblatt, Contextual Design: Defining Customer-Centered Systems. San Diego, CA, USA: Academic Press, 1998.

[34] J. W. Creswell, Educational research: Planning, conducting, and evaluating quantitative and qualitative research, vol. 4. 2012.

[35] J. W. Creswell, Research design : qualitative, quantitative, and mixed methods approaches, 4th ed. Sage Publications, 2014.

[36] J. Amado, Manual de investigação qualitativa em educação, 2* EDIÇÃO. Coimbra: Imprensa da Universidade de Coimbra, 2014.

[37] P. Erikssonand A. Kovalainen, QualitativeMethods in Business Research: A Practical Guide to Social Research. SAGE Publications, 2015.

[38] M. Paul, E. Jean, and M. Bamberg, Qualitative Research in Psychology, First Edit. American Psychological Association, 2003.

[39] J. Saldaña, The Coding Manual for Qualitative Researchers, Second Edi. London, UK: SAGE PublicationsLtd, 2013.

[40] L. Bardin, Análise de Conteúdo. São Paulo, 2012.

[41] J. Corbin and A. Strauss, "Grounded Theory Research: Procedures, Canona and Evaluative Criteria," Zeitschrift fur Sociol., vol. 19, no. 6, pp. 418-427, 1990.

[42] C. P. Coutinho, "A qualidade da investigação educativa de natureza qualitativa: questões relativas à fidelidade e validade," Educ. Unisinos, vol. 12, no. 1, pp. 5-15, 2008.

[43] J. W. Creswell, Qualitative Inquiry and Research Design, Second Edi. Sage Publications, 2007.

[44] E. Taylor-Powell and M. Renner, "Analyzing Qualitative Data," Screen, vol. 25, no. 3, pp. 2-10, 2003.

[45] J. Clark and A. Paivio, "Dual coding theory and education," Educ. Psychol. Rev., vol. 3, no. 3, pp. 149-210, 1991.

[46] C. Luis, H. Afonso, and M. J. Marcelino, "Low literacy adults education: Towards a holistic view of the context," 2019 Int. Symp. Comput. Educ. SIIE 2019, 2019.

\section{AUTHORS}

I am a IT teacher/trainer at Instituto de Emprego e Formação Profissional de Coimbra (IEFP), Portugal, and currently attending the doctoral program of the Department of Computer Engineering of the Faculty of Science and Technology of the University of Coimbra, being my doctoral thesis project subordinated to the theme "A contribution to accessibility and usability in learning environments for literate people". I was very interested in e-learning educational projects. My focus is to develop and/or study environments that can contribute to make the education more accessible to adults, combining new technologies of teaching and learning (virtual learning environments) to accessibility and usability needed for this group of individuals. The paper should be of interest to readers in the areas of Adults education and Human-Computer-Interaction (HCI). 